\title{
HISTORIA Y ESCRITURA CORPORAL EN LA POESÍA CHILENA Y CANADIENSE CONTEMPORÁNEA*
}

\section{Naín NómeZ $Z^{* *}$ Fernanda Moraga*}

\section{RESUMEN}

El artículo establece un recorrido panorámico por las diferentes estrategias textuales que la poesía de mujeres chilena y canadiense ha utilizado desde fines del siglo XIX hasta fines del siglo XX. En el trabajo se analizan sus contextos específicos y sus diferencias geográficas y culturales, pero también se muestran ciertas bases comunes basadas en la relación escritura-cuerpo y en la construcción de sujetos que buscan instalar su historia personal y colectiva a partir de un discurso de ruptura y crítica.

Palabras claves: Poesía chilena, poesía canadiense, escritura, cuerpo, identidad.

\section{ABSTRACT}

This paper establishes a panoramic journey through different textual strategies that Chilean and Canadian women poets have used from the end of the Nineteenth Century up until the end of the Twentieth Century. Specific contexts and geographic and cultural differences are analysed, but we also show certain common foundations related to writing-body relationships and subject construction that seek to install a personal and collective history through a rupturist and critical discourse.

Keywords: Chilean poetry, Canadian poetry, writing, body, identity.

Recibido: 05.05.2006. Aceptado: 27.10.2006.

* Este trabajo se origina en una ponencia presentada en el XXVI Simposio Internacional de Literatura auspiciado por la Universidad de Los Lagos (2005) y es parte del proyecto Fondecyt 1050321 (2005-2007).

** Profesor Titular del Departamento de Lingüística y Literatura de la Universidad de Santiago, Chile. E-mail: nnomez@lauca.usach.cl

*** Profesora de la Universidad Católica Cardenal Silva Henríquez. Estudiante de Doctorado en Literatura de la Universidad de Chile. Santiago, Chile. 


\section{INTRODUCCION}

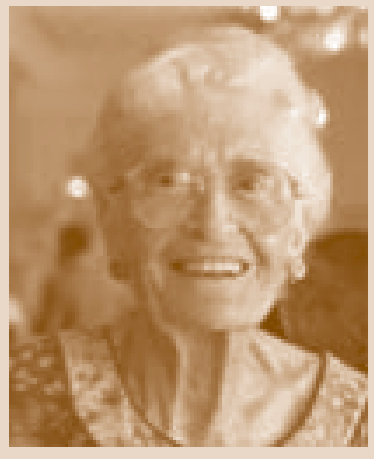

D. Livesay

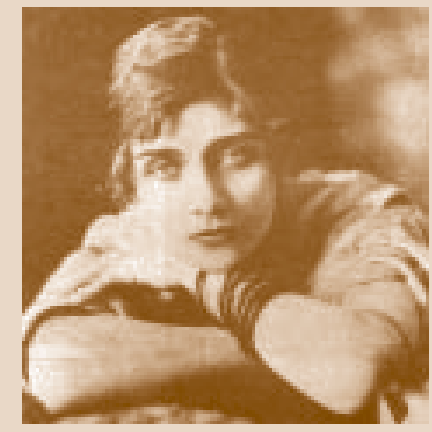

T. Wilms Montt
¿Qué importa si la canción es condenada anulada o vaciada o desmembrada y destruida miembro por miembro? Las palabras existen como las semillas se declaran en el aire más allá de las murallas, en el oído escondido bajo las grietas de la puerta.

(DoRothy Livesay)

Nada tengo, nada dejo, nada pido. Desnuda como nací me voy, tan ignorante de lo que el mundo había. Sufrí y es el único bagaje que admite la barca que lleva al olvido.

\section{(Teresa Wilms Montt)}

La mujer yace en el mojado piso de cemento bajo la luz interminable, hay marcas de agujas en sus brazos para matar el cerebro y se pregunta por qué se está muriendo.

Se está muriendo porque lo dijo.

Se está muriendo en nombre de la palabra.

Es con su cuerpo, silencioso

y sin dedos, que está escribiendo este poema.

(Margaret Atwood)

Lleno de sangre el hocico y la mirada

y entero el cuerpo destrozado

de la presa en su entraña

regurgitando y expirando

expirando y regurgitando

para que ella muriera

y con ella murieran

los cantos de amor y muerte.

(Marina ArRate)

Me ofreciste fuego para encender mi cigarrillo

Pero cuando me incliné a la llama

me chamusqué las cejas y el pelo

Ahora pasa siempre lo mismo - No importa donde nos juntemos, me quemas. 
Siempre tengo que detenerme y frotarme los ojos

$\mathrm{y}$ sacudir el fuego que vive en mi pelo.

\section{(Gwendolyn MacEwen)}

Se me hielan los pies, herma. Todas esas partes perdidas que reviven mi nostalgia. Me hielo y me deshielo dentro de la última guarida de mi cuerpo. La piel se me deshace en gelatina. La sangre avanza un centímetro por segundo. Los dedos congelados no quieren soltar la fibra roja del tiempo.

me cubre una capa de rocío, me cubre el reboso viejo de la ventisca. Ya sólo me removerá la guadaña y yo termino en soledad de cubrirme a mí misma, en esa cama gigantesca de la sábana blanca y helada.

(Elvira Hernández)

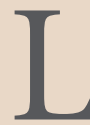

OS FRAGMENTOS anteriores provienen de textos de poetas canadienses y chilenas escritos durante el siglo XX y nos dan el pretexto para preguntarnos por la premisa básica de estas notas: ¿Qué es lo que une a estas poetas de los dos extremos del continente? ¿Es posible que la matriz generadora de estos poemas tenga puntos de encuentro? ¿Existe una sensibilidad común que permita establecer similitudes de culturas tan distintas como son la canadiense y la chilena?

\section{HISTORIA Y LITERATURA DE MUJERES A COMIENZOS DEL SIGLO XX}

Desde los comienzos del siglo XX, la escritura de mujeres se convirtió en un signo evidente de los cambios que el proceso de la modernidad capitalista había cimentado en el mundo occidental en forma desigual entre metrópoli y periferia. Este proceso se consolida con contradicciones en la globalización o mundialización económica y cultural y el neoliberalismo de fines de ese mismo siglo, al mismo tiempo que sustenta la crisis crónica de una modernidad esplendorosa en su universalidad, pero llena de trizaduras en la concreción de las políticas nacionales. Como resultado produce la fragmentación de espacios, hábitat familiar, costumbres e ideas y reproduce también cambios evidentes en las relaciones de género al instalar un parecido sentimiento de desgarro en el imaginario y las visiones de mundo de hombres y mujeres ${ }^{1}$.

\footnotetext{
${ }^{1}$ Desgarro parecido, pero no similar. En Canadá, las mujeres emigran del campo a la ciudad, atraídas por las oportunidades de trabajo del capitalismo en expansión y creando organizaciones
} 


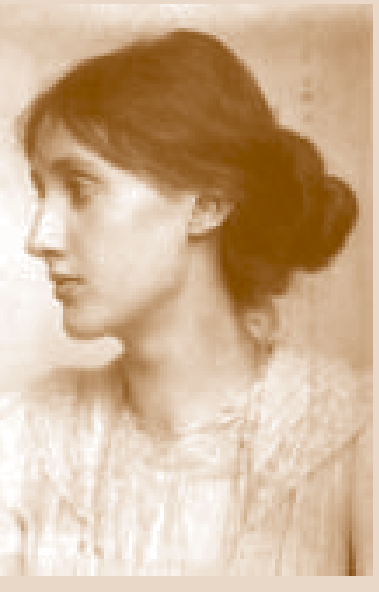

V. Woolf
El siglo XX es el siglo de la escritura de mujeres, no porque antes las mujeres no escribieran, sino porque lo hacían desde otras perspectivas, subalternas, menos reconocidas, desde géneros despreciados, sin el cuarto propio que pedía Virginia Woolf, desprovistas de estatus, rol social y salida al lugar público. Los textos citados marcan la huella de un recorrido discursivo que pretende convertir la construcción de la interioridad en una re-escritura de la historia alternativa, realizada a partir de una realidad histórica diferente de la racionalidad 'objetiva', que alaban algunos literatos del período. Al unir la producción poética de los inicios del siglo XX con la de su final en una vuelta de tuerca, para un proceso que se sigue transformando, tratamos de pautear los prolegómenos de una historia discursiva que se teje lentamente desde orígenes difusos, represiones oblicuas y carencias inobjetables. Al comparar a poetas de países tan disímiles como Canadá y Chile (y aquí sólo nos referimos al Canadá inglés), tratamos de argumentar que es más importante el gesto de reconstrucción genérico de identidad, que las diferencias linguísticas, geográficas y culturales. Es indudable que existen desarrollos desiguales en los procesos independentistas, los flujos de inmigración, la exploración de territorios, la simbiosis racial, las influencias de la metrópoli, el crecimiento demográfico y económico, el desenvolvimiento político, la ligazón con la religión y otros rasgos que expresan la diferencia. Hay procesos culturales que se adelantan o se retardan de acuerdo con los traspasos que provienen desde el centro o con la asunción de nuevas identidades, pero al mismo tiempo la expansión y globalización del sistema capitalista, cuando se inicia el siglo XX, hace emerger nuevas capas sociales y sectores urbanos que masifican la producción cultural en todos lados y le da cabida a las mujeres como nunca antes.

En los albores del siglo XX, la literatura de mujeres se desarrolla en Chile a la par del emergente proceso de modernización capitalista que exige también una forma de capital en el campo cultural educativo, especialmente focalizado hacia las capas medias y obreras. Se multiplican las escuelas, las universidades y los periódicos (en 1914 llegan a 531 en el país). La revista Zig-Zag vende en 1905 cerca de 100 mil ejemplares. La competitividad del intercambio productivo en el campo cultural moviliza no sólo a los escritores, sino también a los críticos, los académicos, los editores, los pedagogos, los antologadores y los jurados. La escritura de mujeres, que durante siglos

que les dan un sentido de identidad. Pero al mismo tiempo, la continuidad de las luchas domésticas, la diferencia de pago con los hombres, las censuras y las restricciones remarcan una crisis en los roles, que desde el otro sexo, desminuido en su tradicional patriarcalista, también se hizo evidente. En Chile, aunque hubo un desarrollo parecido, las condiciones fueron distintas. Desde el punto de vista económico, un capitalismo periférico; desde el punto de vista cultural y político, el ascendiente religioso y la tradición hispánica impedían a las mujeres adoptar un rol público activo, ya que las exponía a la befa, el sarcasmo, el repudio y al rótulo de 'mujer de la calle', el peor insulto en una cultura históricamente machista. 
estuvo constreñida a discursos íntimos y privados como el diario de vida, la autobiografía, el testimonio, las epístolas y los pensamientos, busca ahora comunicarse con los otros y especialmente con las otras. Emerge en periódicos y arengas como protesta genérica doble: contra la represión sexual y económica, pero también como discurso reprimido desde siempre. Decenas de mujeres hacen versos, pero son pocas las que cuestionan el discurso del poder o del canon patriarcal. Es así como la poesía de mujeres se entroniza y difumina en forma residual con el proceso de la modernidad y los modos discursivos ejemplares de la época. Mientras en el campo cultural se relevaban las obras de 'vanguardia' de un Huidobro, un Neruda o un Pablo de Rokha, las 'identidades tránsfugas' (A. Valdés) de las mujeres se pierden en el imaginario simbólico dominante y un aparato crítico ultraconservador y misógino ${ }^{2}$.

Algo parecido ocurre en este terreno en Canadá, aunque con la diferencia de sus vastos territorios, el predominio de dos lenguas y de dos culturas dominantes y la cercanía de Estados Unidos. Desde la conformación de la Confederación en 1867, las mujeres empiezan a ganar espacios en la medida en que la industrialización capitalista necesita nueva mano de obra y la formación de nuevas profesiones. La población crece de 2,5 millones en 1851 a 9 millones en 1921, expansión que se acelera con la llegada de grandes grupos de inmigrantes, no sólo de habla inglesa sino también de Europa, Asia y el Caribe. Tal como en Chile, a comienzos del siglo XX se produce una fuerte migración del campo a la ciudad y las mujeres pasan de trabajar en labores domésticas y cuidar los animales a emplearse en las fábricas, elevar su educación y trabajar en salud, medios de comunicación, oficinas, colegios y negocios. Por otro lado, las desigualdades sociales y económicas llevan a las mujeres a organizarse no sólo para defender sus derechos, sino también para reflexionar acerca de sus diferencias de género y su sumisión en un mundo patriarcal $^{3}$.

Desde la perspectiva de la producción poética, las pioneras canadienses inglesas hacen del paisaje una expresión de sus sentimientos al mismo tiempo que ofrecen retratos melodramáticos de sí mismas con un fuerte resentimiento hacia la dominación masculina. Es el caso de Isabella Valancy Crawford (1850) y Pauline Johnston (1861), poetas descriptivas, impregnadas de un énfasis animista que integra paisajes y sentimientos, o la curiosa presencia de Louise Morey Bowman (1882), adelantándose a su tiempo con poemas coloquiales de cierto vanguardismo que también bucean en las represiones del género.

\footnotetext{
${ }^{2}$ Adriana Valdés, “Identidades tránsfugas”, en Una palabra cómplice. Encuentro con Gabriela M istral (Roma-Santiago: Isis Internacional, 1989), pp. 75-86.

${ }^{3}$ En esta sección, seguimos de cerca la obra Canadian Women. A History, de Alison Prentice et al. (Toronto: Harcourt Brace and Co., 1996), especialmente las secciones 2 y 3.
}

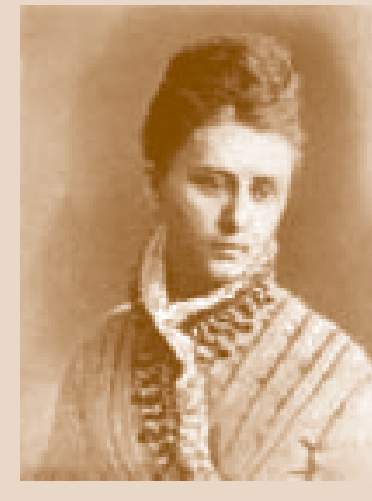

I. Valancy Crawford

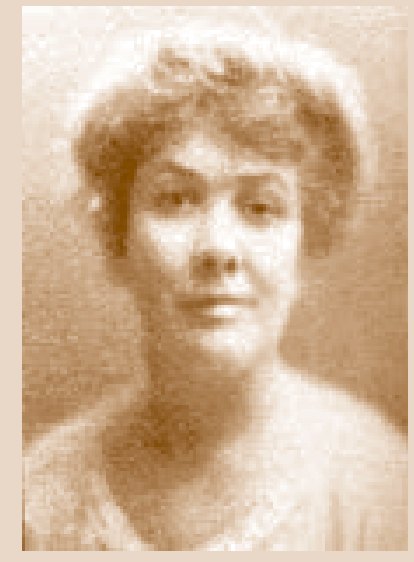

L. Morey Bowman 


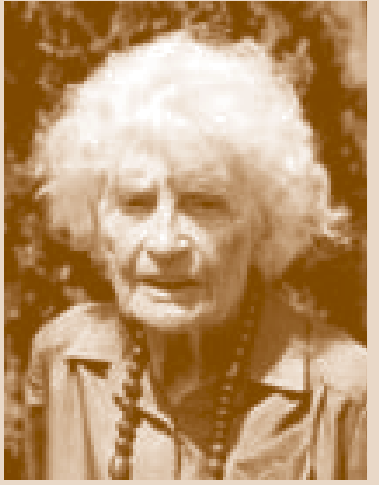

D. Livesay

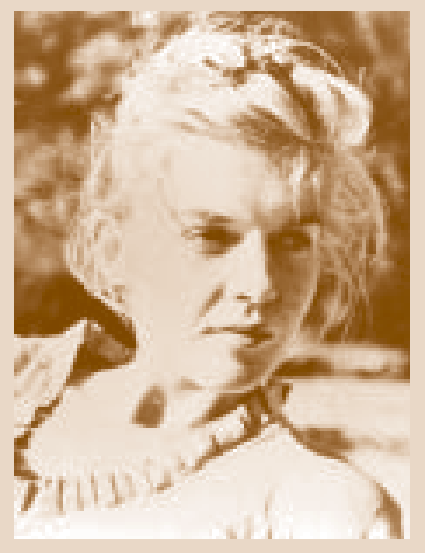

E. Smart

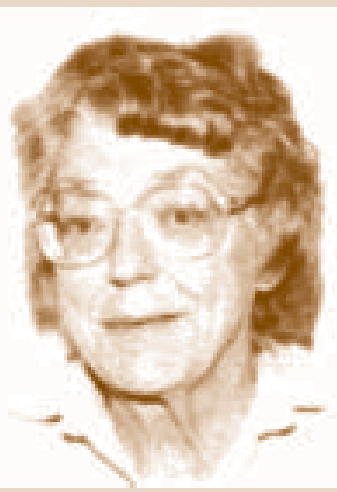

A. Marriot
Recién hacia los años 30 del siglo XX empezarán a aparecer algunas poetas mujeres que se articulan a la poesía moderna con un gesto personal que integra una visión política con una búsqueda de sí mismas. Es el caso por ejemplo de Dorothy Roberts (1906), Dorothy Livesay (1909), Anne Wilkinson (1910), Elizabeth Smart (1913) y Anne Marriot (1913). Ellas, si bien no forman un grupo compacto, permiten desarrollar una multiplicidad de tendencias que se desprenden de las fuentes inglesas y norteamericanas, centrándose en las temáticas de la identidad, los conflictos culturales y la relación con Estados Unidos. En Dorothy Roberts y Anne Marriot, por ejemplo, se percibe un sujeto que busca restablecer sus ligazones familiares en comunión con un escenario natural empático y una mirada que va creando su propio mundo interior. El paisaje canadiense es una manera de revelar las relaciones del trabajo cotidiano con las emociones personales, los amores, las angustias y las percepciones sobre el hombre. Anne Wilkinson desarrolla una mirada crítica, a veces denostando el exterminio de la guerra, la inutilidad de la política o el establecimiento de una nueva visión poética desde la mujer. Pero es probablemente Dorothy Livesay quien más fuertemente busca ligar la situación de la mujer con la naturaleza violentada por la guerra, la violencia y la represión. Comprometida políticamente con el Partido Comunista, Livesay parte haciendo una crítica de la injusticia para terminar explorando los diferentes roles que ha asumido la mujer de su tiempo, así como la necesidad que tiene de controlar su propia vida. Como señala Rosemary Sullivan ${ }^{4}$, Livesay modela ya a fines de los veinte ese sentido de comunidad literaria y vital que se desenvolverá en los distintos bolsones de la cultura canadiense. En ella se agitan no sólo diversos temas, sino también diferentes modos de apropiarse del lenguaje que van desde una imaginería surrealista hasta formas casi narrativas con sus diálogos e intercalaciones. En textos como "The Notations of Love" (Anotaciones amorosas), la levedad del verso sugiere ya la construcción de un sujeto que ha empezado a cuestionarse desde las raíces su afectividad y su relación con el mundo:

No me dejaste nada, cuando

me desnudaste a la luz

con suavidad me quitaste la piel

me desvestiste hasta el hueso.

No me dejaste nada, pero lentamente me derretí

en la tierra verde

el pasto creció entre mis muslos.

Y cuando una flor salió disparada

\footnotetext{
${ }^{4}$ Rosemary Sullivan en "Introduction”, Poetry by Canadian Women (Toronto: Oxford University Press, 1989), p. XII.
} 
desde mis dientes desenganchados

no me dejaste nada sino la lengua para decirlo ${ }^{5}$.

En otro fragmento, agrega:

Solo los labios permanecen frescos

solo la lengua desenvaina su piel secreta

y pone cerrojo al relámpago ${ }^{6}$

con lo cual establece para el concepto de 'lengua' un campo semántico de varia riqueza que involucra tanto la producción literaria y la posibilidad de hablar y expresarse sobre todo a partir de una oralidad siempre censurada por ser pasajera, como así mismo una simbólica sexual de la mujer que se opone al falocentrismo expresado en la cultura patriarcal. El texto de esta poeta aparece ya como un potencial de producción de sentidos abierto a la lectura múltiple.

En Chile, el proceso de modernización de comienzos de siglo tiene su caso paradigmático en la figura de Gabriela Mistral (1889). Tal vez la diferencia con el contexto en que se desarrolla la escritura de mujeres en Canadá es que la represión escritural es más directa en Chile e impide un desarrollo propio de las mujeres a no ser que se imite la escritura masculina. Si Mistral es aceptada, es porque su obra se descodifica a través de una superposición biográfica inocua, porque es invitada a México a entregar su experiencia como educadora, porque su falta de encanto corporal la hace aséptica en su trato con los hombres y porque se le endosa el estereotipo de la maestra sufriente, religiosa, maternal y afectuosa. Una nueva crítica ha logrado desmenuzar la apariencia mansamente filial de la obra mistraliana, para mostrarla escribiendo sobre la mujer nueva y establecer a través de su delirio poético el deseo de la mujer que quiere ser, pero que la represión no le permite. Como se ha señalado, la obra de Mistral se alimenta de un desgarro esencial que viene de la herida paterna y escribir versos es para ella abrir esa herida y poner de manifiesto ese desgarro: el de ser una y querer ser la otra, la loca, la alucinada, la productora de versos, la que desafía la Ley del Padre, la que anda en la niebla como fantasma, la extranjera que como ella misma señala: "Vivirá entre nosotros ochenta años, / pero siempre será como si llega, / hablando lengua que jadea y gime / y que le entienden solo bestezuelas. / Y va a morirse en medio de nosotros, / en una noche en la que más padezca, / con sólo su destino por almohada, / de una muerte callada y extranjera"7.

5 "Anotaciones amorosas" en Un pájaro es un poema, Lake Sagaris, ed. (Santiago: Pehuén Editores, 1986), p. 129. Traducción de Lake Sagaris.

${ }^{6}$ Ibid, p. 131.

7 "La extranjera" en Poesía chilena contemporánea, Naín Nómez, ed. 2a ed. (Santiago: Fondo de Cultura Económica, 1998), p. 46.

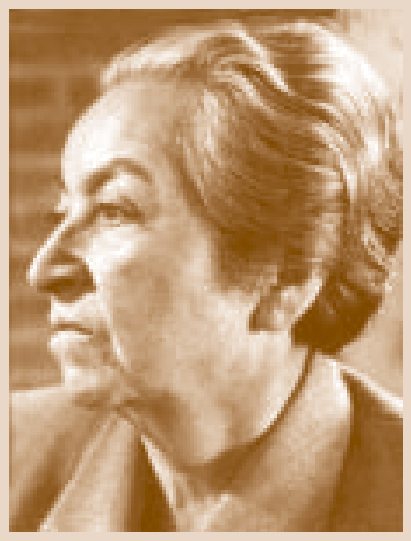

G. Mistral 


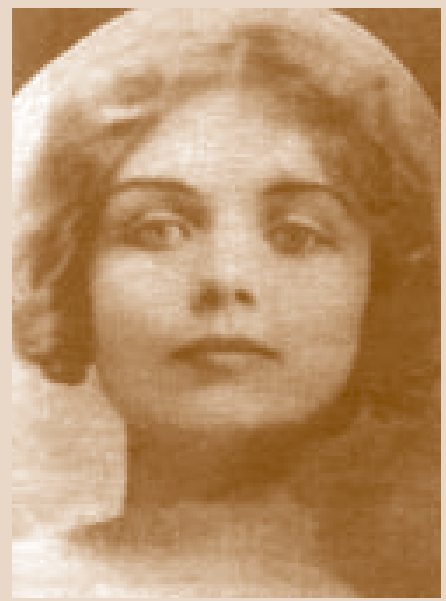

T. Wilms Montt

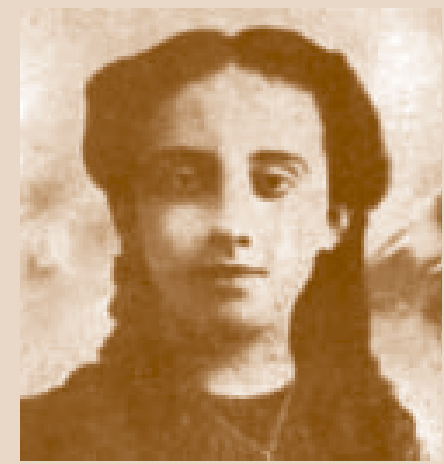

W. de Rokha
El proceso modernizador que se instala en Chile en los años veinte incorpora otras poetas al sistema cultural, las cuales asumen el proceso social y personal con variadas visiones que buscan consolidar la mirada de un sujeto aprisionado en su gestualidad creativa. Teresa Wilms Montt (1893) es un caso paradigmático de represión y censura. Oveja negra del rebaño de la elite chilena, su leyenda biográfica supera con creces el conocimiento de sus escritos, publicados en forma completa sólo en 1994. Enamorada de un burócrata, se casa a los 17 años contra la voluntad de sus padres, le arrebatan a sus hijas, no le conceden el divorcio, la encierran en un convento cuando se enamora de otro hombre, es condenada por confesar sus amores, vive en el desarraigo permanente durante el resto de su vida por medio de un periplo que la lleva de Santiago a Buenos Aires, Nueva York, Madrid, París, Buenos Aires y finalmente a París, donde se suicida, abandonada y sola, a la edad de 28 años. Enmarcada en el estereotipo de la femme fatale, debe renunciar a todo como castigo por dedicarse a escribir y exteriorizar su intimidad. A diferencia de Mistral, que se enmascara como la educadora de los pueblos y vacía su maternidad en el discurso, Wilms Montt se expone a todos los amores y señala que "cerca de todos los hombres me siento maternal". Producto del advenimiento de la modernidad que libera económicamente a la mujer a condición de mantener su subalternidad genérica, Teresa Wilms se descubre a sí misma como sujeto capaz de producir, indignarse o expresar su solidaridad en forma privada y pública. Como Mistral se refugia en la Otra, pero esta Otra no es sólo la del discurso, sino también la Loca de amor apasionado que se desintegra en el espejo vacío de los sueños y culmina en la tragedia: "Como en un abismo sin fin, me hundo en mi pasión... ¿Será la locura el fin de nuestra historia?”. Si bien el imaginario interior es un refugio contra los males del mundo, también es la representación del resquebrajamiento de todo proyecto que intente romper el orden erigido por el mundo patriarcal. A días de su propia muerte, señalará en su "Diario" con un discurso cada vez más alterado, agitado y fugaz: "extraño mal que me roe, sin herir el cuerpo va cavando subterráneos en el interior con garra imperceptible y suave... desnuda como nací me voy"s. Su imaginario alternativo culmina en el fracaso de su proyecto de vida y en la invisibilidad del texto.

De las otras poetas que empiezan a escribir en los años veinte, tal vez se salvan parcialmente del ostracismo y la tragedia, Winétt de Rokha (1894) y Olga Acevedo (1895), en ambos casos porque lucharon denonadamente (como Dorothy Livesay) por los derechos de las mujeres, la justicia y la solidaridad. Winétt de Rokha, más bien conocida por ser la esposa del poeta

\footnotetext{
${ }^{8}$ En la sección IV de su "Diario" publicado en O bras completas por Ruth González-Vergara (Santiago de Chile: Editorial Grijalbo, 1994), pp. 169-201.
} 
Pablo de Rokha, debió pagar el precio de la personalidad desbordante de su marido, dejando una obra casi desconocida para la crítica coetánea y actual, obra sin embargo de gran interés porque se enquista en la vanguardia sin dejar de mantener un tono íntimo y austero que se contradice con el de su esposo. Por su parte, Olga Acevedo debía escribir a escondidas de su marido, lo que la lleva a divorciarse y a volcarse en la lucha social y gremial, esfuerzo que también opacó su obra fuertemente vanguardista y en la que se perciben permanentes transformaciones e innovaciones.

\section{SEMEJANZAS Y DIFERENCIAS EN LA SEGUNDA MITAD DEL SIGLO XX}

A diferencia de la poesía canadiense inglesa, las poetas que escriben con posterioridad no consolidan en Chile una escritura que se amplíe y se ponga a la par con la escrita por hombres. Es posible que un contexto de avances y retrocesos en la batalla por sus derechos haya influido en este terreno. Volcadas en la lucha por la reivindicación personal, política y social o refugiadas en un intimismo reprimido, las mujeres más liberales -y entre ellas las poetas- tienen un retroceso enorme cuando en los cincuenta la senadora María de la Cruz es destituida y su poderoso Partido Feminista deja de existir. La fuerza telúrica y política de la vanguardia poética con sus experimentos formales, instalada en Chile con nombres como Neruda, Huidobro, De Rokha, Díaz Casanueva, Rosamel del Valle o el tardío grupo surrealista La Mandrágora, no deja resquicios a las poetas mujeres, que refugiadas en una intimidad que las construye y las limita, aparecen en lugares secundarios bajo el rubro de lo 'femenino', es decir lo nimio, banal o simple. En los 30' y $40^{\prime}$ y 50 ', poetas como Chela Reyes, María Tagle, María Isabel Peralta, Gladys Thein, Mila Oyarzún, Stella Corvalán y otras, hacen aportes diversos que apenas son considerados en algunas antologías, pero siempre dentro del tono menor que se le asigna a la escritora mujer. No conforman grupos ni generaciones contestatarias, pero además se trata de un fenómeno que no ha tenido recepción ni interés para la crítica. A ello se agrega el problema del mercado de un género sospechoso y difícil en un país tercermundista con un mercado exiguo y donde lo propio es despreciado. Las novedades siguen viniendo de Londres, París o Nueva York y en eso no hay diferencia con lo que ocurre en el mercado literario canadiense de esos años. Los canadienses, como señala Margaret Atwood en Survival ${ }^{9}$, se sienten periféricos y viviendo en la colonia cultural y económica. Esta situación solamente empieza a cambiar en los sesenta, cuando la audiencia de los poetas se hace tan

\footnotetext{
${ }^{9}$ En Margaret Atwood, Survival (Toronto: McClelland \& Steward Inc., 1996), pp. 25-43.
}
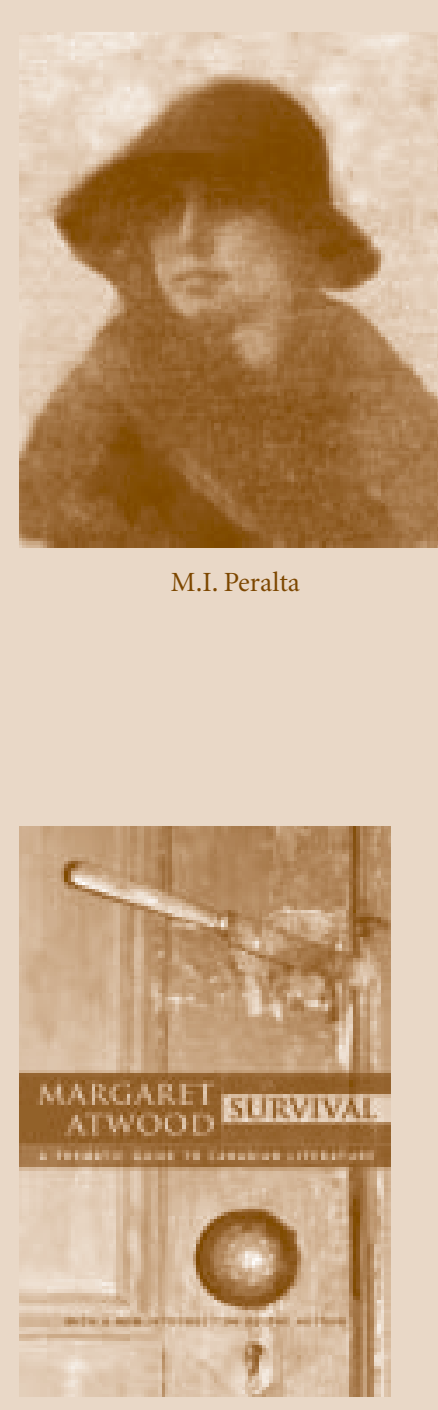


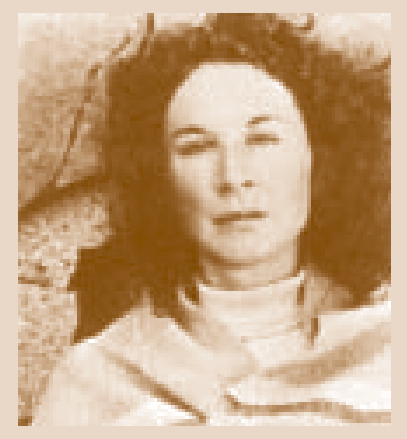

M. Atwood

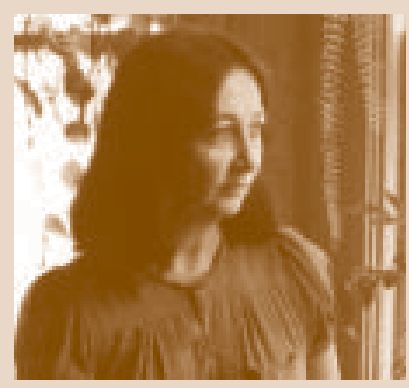

G. Mac Ewen

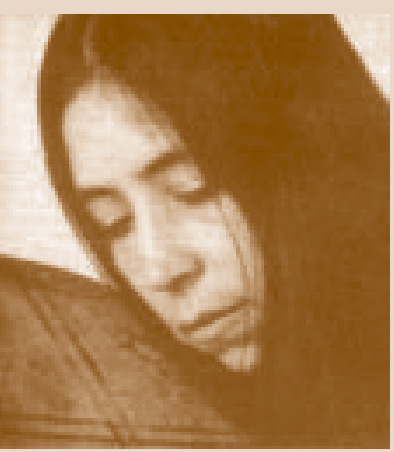

C. Vicuña masiva como la estadounidense y en los setenta ocurre lo mismo con los novelistas. Durante el período que va de los cuarenta a los sesenta, la poesía de mujeres en Canadá es comparable a la de los hombres, multiplicándose en nombres y obras que compiten por premios y público. Es el caso de P.K. Page (1916), Margaret Avison (1918), Elizabeth Brewster (1922), Phillis Webb (1927), Adele Wiseman (1928) y Pat Lowther (1935), entre otras. Ellas exploran formas, contenidos, temas metafísicos y experimentos con el lenguaje, transformando la literatura canadiense en algo propio con una identidad variada y compleja, que a partir de allí se transforma permanentemente. En los setenta, esta amplia visión se acentúa con la puesta en escena de poetas como Margaret Atwood (1939), Gwendolyn Mac Ewen (1941), Daphne Marlatt (1942), Bronwen Wallace (1945), Susan Musgrave (1951), Lorna Crozier (1948), Roo Borson (1951) y así al infinito. El proceso de la escritura de las mujeres en el Canadá inglés es un fenómeno integral que se desarrolla a partir de una tradición propia que se articula y sostiene por sí mismo, pero también en diálogo, integración y discusión con la poesía masculina.

La situación chilena fue distinta. Como anunciamos antes, ni siquiera la apertura generosa de los sesenta fue suficiente para liberar la voz de las poetas mujeres. Apenas una o dos poetas alzan su voz en el período y la más importante -Cecilia Vicuña- se va a vivir a Estados Unidos, donde su ligazón con los grupos beat y el hippismo serán claves en la continuidad de una obra que se entremezcla con acciones de arte y tradiciones indígenas. Hasta la ruptura autoritaria del golpe de estado del 73', la poesía masculina había mostrado un desarrollo incomparable en un juego de rupturas y continuidades permanentes. A las voces de los patriarcas que seguían hablando con voz tonante (Neruda, De Rokha, Díaz Casanueva, Anguita) se agregan ahora las rupturas y críticas de nuevos poetas que rompen con los discursos de la vanguardia y acercan la poesía a la oralidad, el coloquialismo y la claridad del hombre común: es el caso de Nicanor Parra (1914), Gonzalo Rojas (1917), Enrique Lihn (1920) y Jorge Teillier (1935). Otros poetas importantes del período serán Efraín Barquero, Miguel Arteche y Armando Uribe.

Pero el golpe de estado cambia el escenario. Los poetas emergentes de los sesenta que se afianzan en un mundo urbano desmantelado o en la nostalgia de un hogar rural utópico y perdido (el caso de Waldo Rojas, Oscar Hahn, Manuel Silva Acevedo, José Angel Cuevas, Gonzalo Millán, Floridor Pérez, Jorge Etcheverry y otros), se quedan a medio camino y son escindidos geográfica y visceralmente. Muchos salen al exilio y van a incorporar las nuevas geografías en su escritura. Diversas generaciones coexisten con textos que van desde la denuncia y el testimonio hasta la exploración exhaustiva de los propios fantasmas y una experimentación medular con el discurso. Las promociones emergentes que comienzan a escribir en los setenta son censuradas o autocensuradas y a partir de allí se gesta una matriz literaria de diver- 
sas líneas que en forma sibilina y críptica intenta conformar lenguajes de multívocos sentidos y lecturas secretas. A partir del liderazgo de algunos poetas neovanguardistas como Juan Luis Martínez, Raúl Zurita, Diego Maquieira o Rodrigo Lira, se genera un discurso que critica la ultramodernidad neoliberal con su fetichismo del mercado, desde un sujeto que se sitúa en los márgenes de la sociedad, que se autoaniquila y mutila y que habla en los vacíos y los intersticios del lenguaje. En esta exploración, que se desarrolla como búsqueda de lenguajes nuevos que den cuenta de la situación de represión que se vive en el país, surge en los últimos veinte años la representación de la variada gama de voces de poetas mujeres que participan en un escenario donde todo está por hacer. Es el caso de Soledad Fariña (1943), Carmen Berenguer (1946), Elvira Hernández (1949), Eugenia Brito (1950), Carla Grandi (1947), Verónica Zondek (1953), Teresa Calderón (1955), Paz Molina (1945) y Marina Arrate (1957), entre otras.

\section{POETAS DE VIGENCIA ACTUAL}

La inversa situación que se produce en ambos países a partir de los sesenta, curiosamente produce un fenómeno con ciertas similitudes, aunque probablemente los efectos sobre la publicación, la circulación y la recepción de los productos literarios sean diametralmente distintos. En Canadá, las lecturas de café, las pequeñas empresas editoriales, el afianzamiento del nacionalismo cultural, la fundación del Consejo Nacional de las Artes, la CBC, crean un clima de confianza cultural que incentiva la producción de más de 2 mil poetas. No es la única causa, por supuesto, pero incide en la amplitud de una discusión cultural que también se desborda a las revistas y otros medios de comunicación, creando la sensación del surgimiento de una identidad y una cultura propia. La poesía se vuelve hacia el mito indígena, la exploración del paisaje y los nuevos descubrimientos de la historia colectiva y personal. En Chile, por el contrario, a los sesenta apoteósicos y desbordantes en actividades aunque más mesurados en creatividad, se suceden los setenta censurados, etapa obscura que con distintos matices se remontará hasta los noventa. En este contexto es donde podemos percibir ciertas similitudes en los discursos de las poetas de ambos países, similitudes que se nos aparecen teniendo en cuenta todas las diferencias de que hemos hablado más arriba, incluyendo un desarrollo historico evidente, pero geográficamente diverso en el caso canadiense, en comparación con un discurso que surge de la oscuridad de un contexto censurador que obliga a inventar lenguajes y códigos nuevos que multiplican sus sentidos al infinito en Chile. No es que no existan voces testimoniales o de denuncia directa, ni tampoco que no haya poetas que establezcan una continuidad con la tradición anterior. Pero el fenómeno más relevante tiene que ver con una escritura que con diversos

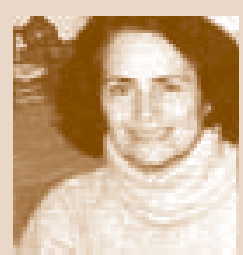

S. Fariña

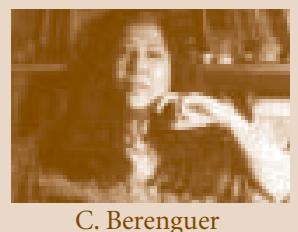

C. Berenguer

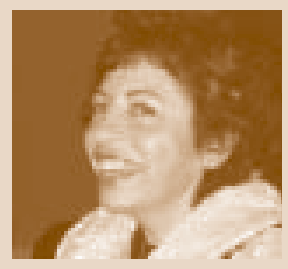

T. Calderón

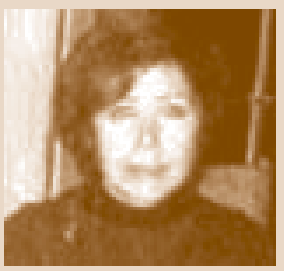

E. Brito

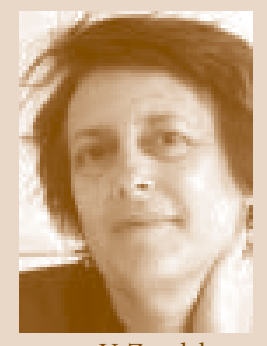

V. Zondek

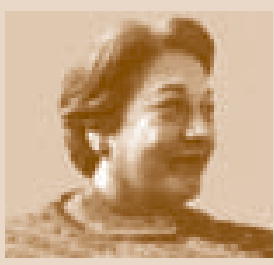

P. Molina

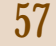

Atenea 494 II Sem. 2006 


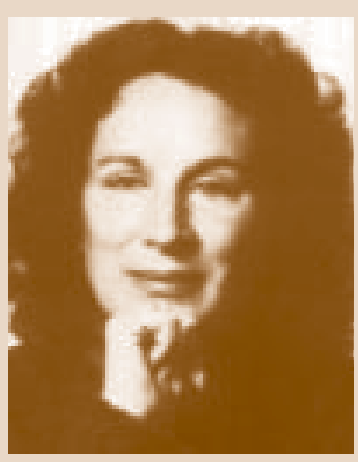

M. Atwood

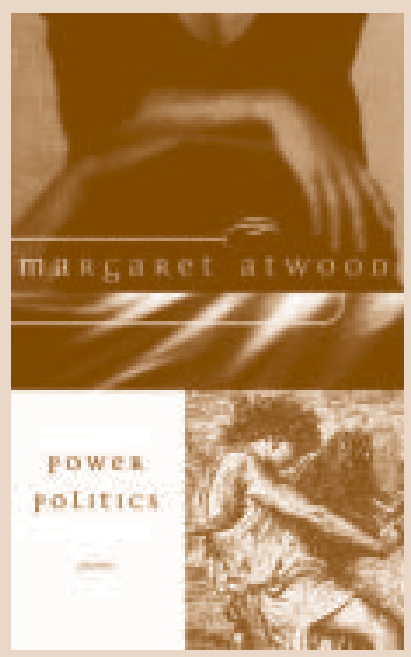

matices apunta a re-escribir la historia personal y colectiva con el cuerpo, liberando en la misma búsqueda, cuerpo, lenguaje e historia. Esta poética femenina que recorre un amplio abanico de posibilidades se muestra como la búsqueda de una identidad -de texto y de sexo-, a través de un discurso que inscribe la imagen del cuerpo al mismo tiempo que evoca la imagen de lo reprimido al hacerse ambivalente, móvil y fragmentario.

En Canadá la figura de Margaret Atwood, prima donna de su literatura, ha coincidido con una obra que expresa la búsqueda del conocimiento sobre el ser mujer, que se origina en el intento de transformación y mutación del otro. El espíritu mítico que alimenta la obra de Atwood es sólo el puente que le permite volver a reencarnarse en su ser femenino y un pretexto para enunciar temas que la obsesionan: el cambio del mundo de la percepción al mítico, la necesidad del autoconocimiento, el poder de la naturaleza primitiva o la arquetípica búsqueda del padre, elementos que no están ausentes en poetas chilenas como Soledad Fariña, Marina Arrate, Eugenia Brito o Elvira Hernández. Atwood ve al ser moderno como compelido a recibir continuas invasiones de miedo y paranoia que lo asaltan desde la mente subliminal, todavía comprometida con creencias anacrónicas en un orden civilizado, que contradice la barbarie del siglo. Su objetivo es cruzar con la escritura las convenciones que nos inventamos, saltando al lado salvaje y primitivo que las expone y reduce. En su libro de poemas Política del poder (1971) la autora expone las decepciones sadistas implícitas en el mito del amor romántico. Los enamorados son depredatorios y hasta caníbales. Las relaciones son una forma sofisticada de consumo y en el amor se establece una política de poder. Cada individuo busca la seguridad de su rol, reforzándose a través del otro y permanece atrapado en un solipsismo esencial, comprometido sólo con su propio necesario apetito. También Atwood explora las complejidades de ser canadiense y la división de las dos culturas dominantes. En su obra el desafío fundamental es hacernos más humanos por intermedio de una visión redentora y esperanzadora del mundo. Aunque el problema de la identidad pone en contacto las temáticas de ambos países, es indudable que la represión adquiere formas más sutiles en el contexto canadiense, donde los miedos, las fobias y las visiones se originan en mitos culturales y religiosos diferentes. Por otro lado, hay en Atwood una madurez entrañable sobre los problemas del ser femenino y masculino, que no son parte de la experiencia que comparten las mujeres poetas chilenas. Para Atwood, la ligazón colonial con Inglaterra y los Estados Unidos le ha dado a su país una imagen de víctimas, que se reproduce en las obras con los temas de la sobrevivencia, la alienación, el enfrentamiento con una naturaleza hostil y la breve permanencia del amor. Es en este dualismo existencial donde se afincan el poder y la fuerza de la literatura femenina canadiense. Como subraya Alice Munro: 
Es difícil ser mujer en la casa y escritora, porque tradicionalmente la mujer abdica. Ve muchas verdades que prefiere no ver si quiere mantener su situación y las escritoras tienen que ser libres de eso. Los hombres siempre parecen más libres para decir sus verdades... sobre el matrimonio, sobre sus cuerpos, sobre ellos... Muchas escritoras tienen la contradicción interior de ser mujeres ambiciosas y mujeres que quieren ser dominadas, tener algo entre ellas y el mundo. Y yo también soy las dos mujeres ${ }^{10}$.

Esta doble condición va a ser recalcada por Atwood en Survival, especialmente en la dicotomía Mujer de Hielo versus Madre Tierra o el símbolo del Angel de Piedra versus La Venus Ausente, dicotomía que también será incorporada con matices en el contexto de la representación del mundo de las poetas chilenas. En un mundo con una naturaleza desbordante, la Mujer se transforma obsesivamente en diversas mutaciones de la Naturaleza con sus ciclos y fases, de las cuales la figura de Venus es la menos visible y la de la siniestra Hécate que reina sobre la muerte con poderes oraculares es más poderosa, sobre todo cuando se le reprime y se le impide potenciar sus posibilidades de ser mujer. En el medio está la visión de la Vieja Mujer Sabia tan proclive a aparecer en la literatura canadiense. A veces Piedra, a veces Hielo, la Diosa Naturaleza combina a Diana con Hécate, la diosa virginal con la muerte. La imposibilidad de unir la apariencia venusina de la mujer con una interioridad congelada imposible de cambiar, es parte de la temática de un número importante de poemas. Hécate se disfraza, apareciendo como una mujer joven, bella y fogosa, pero en realidad se trata de una mujer fría y represiva, vieja por dentro. La dualidad entre cuerpo y alma es parte de una historia represiva de la cual la autenticidad de la mujer no puede desprenderse. La metáfora de la Mujer-Naturaleza conlleva la figura de una aparente Mujer Sabia Virgen Anciana y Mortuoria que conserva atrapada en su interior las figuras de Venus y Diana que pugnan por liberarse como en el poema de Jay MacPherson "La mujer encuevada":

Lo que empaqueta sus huesos de marfil resulta cruel para el toque maravilloso; su esqueleto duro circula por las raíces de las piedras y no puede dar o confortar demasiado.

Su regazo está sellado para los chubascos de verano, rodeado de hielo y anillado por el acero; su pecho empuja su amor como las flores asombradas en las colinas del frío.

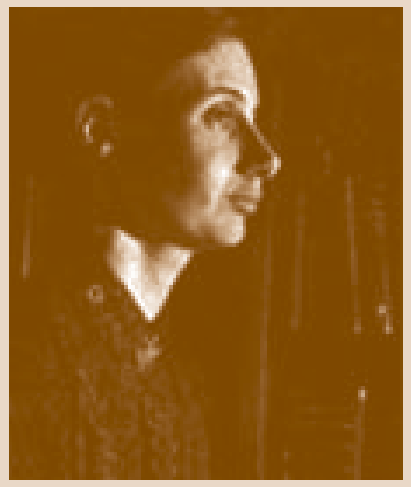

J. MacPherson

${ }^{10}$ Alice Munro en Paul Denham, The Evolution of Canadian Literature in English (Ottawa: Holt, Rinehart and Winston of Canada Limited, 1973), p. 200. 


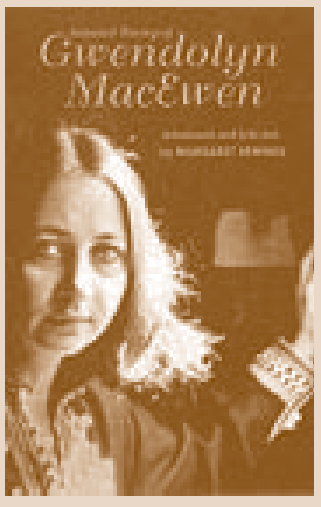

Aquí no está el sol que libera y entibia, que acaricia entre el fuego y el desborde; porque lejos están las formas seráficas: que son flores, fuentes, leche y sangre ${ }^{11}$.

En Gwendolyn MacEwen, la búsqueda de una identidad reprimida o escondida es aún más evidente y se asemeja a ciertos aspectos que en este sentido se pueden encontrar en la poeta chilena Marina Arrate. La diferencia está en que la lucha entre agua, tierra y fuego como parte de la división interior es mucho mas clara en la canadiense. La Madre Naturaleza (Madre Tierra) aparece como el terreno que se quiere reconquistar. En el poema "Me ofreciste fuego", el fuego es un elemento masculino que se impone a la sujeto, que le hace daño, le impide ver la realidad y la inmoviliza: "Me ofreciste fuego... me chamuscó las cejas y el pelo; Ahora es siempre lo mismo... me quemas... tengo que parar y frotarme los ojos / y sacudir el fuego vivo de mi pelo" 12 . Esta imposición altera a la sujeto, la deja fuera de sí misma, la obliga al movimiento para volver a encontrar el arraigo en su origen o su propia intimidad. Así en el poema "El porteo", el cuerpo se transforma en una canoa que navega por el mar masculino que la asedia y la domina, pero que le es ajena: "Hemos viajado con nosotros mismos / ... nos hemos llevado en nuestras espaldas, como canoas / ... buscando el límite, el final / los litorales de esta tierra". El viaje es un recorrido por la interioridad en busca del arraigo que tiene que ver con el origen terrestre, el regazo de la Madre Tierra al que se quiere volver. La sujeto indica que "mensajeros indiscretos nos traían mensajes crípticos desde la orilla... (y) juramos no navegar más". Estos son los mensajeros del origen que a su vez aparecen interferidos por señales opuestas de la naturaleza. Aquí vemos cómo los distintos aspectos de la Naturaleza Mujer se contraponen para mantener o transformar la contradicción entre la mujer interior y la exterior. Signo de ello es el "cielo entumecido", "los cúmulos sombríos que nos pesan", la miel derretida, la "estrepitosa insinuación de truenos" y los "indios (que) están tratando de decirnos / por qué hemos venido". El poema culmina en la imposibilidad, la misma de la cual escribía Atwood más arriba: "Por ahora tenemos el movimiento... (pero) la inmovilidad empavorece... Ya no podemos acarrear / nuestros barcos nosotros mismos / por estos senderos insinuantes"13. El sentido del viaje en busca del arraigo no se encuentra en ningún centro, sino que está en los márgenes, en los bordes. La misma conciencia de moverse también es engañosa, ya que los navegantes siguen en medio del dominio del mar donde el movimiento equivale a no moverse.

\footnotetext{
${ }^{11}$ En Margaret Atwood, op. cit., p. 198. La traducción es nuestra.

12 "El porteo" de Gwendolyn MacEwen en Lake Sagaris, op. cit., pp. 155-157.

${ }^{13}$ Ibid, p. 157.
} 
En el poema "Oscuros pinos bajo el agua", el tema se reitera. Aquí la tierra y el agua son posibilidades de reconquista del ser femenino. El poema empieza señalando: "Esta tierra como un espejo te dobla hacia adentro / y te conviertes en el bosque de un lago furtivo, / los obscuros pinos de tu mente se extienden hacia abajo". El contacto con la tierra hace que la sujeto se mire (la imagen del espejo no es trivial puesto que es, como se sabe, el primer elemento desde el cual Lacan plantea la reconstrucción del sí mismo para el sujeto femenino) y pueda verse a sí misma enraizándose en la tierra, al naturalizarse en la imagen del bosque que integra la mente a las raíces que se extienden hacia abajo. Esto indica que la existencia de la sujeto es subterránea, porque al hundir las raíces en el agua y vincularse a la tierra se está descubriendo lo que hay en el fondo para contarlo y liberarse: "y te hundes, te hundes, durmiente / en un mundo elemental: / Hay algo allí abajo y quieres que se cuente" 14 . En esta búsqueda, la sujeto es una durmiente porque la forma del conocimiento de sí misma evade la racionalidad del mundo construido por el hombre y se hunde en una forma de conocimiento más elemental y primaria, que le permite sacar la voz del silencio y contar su historia.

Otros textos de MacEwen, como "Meditaciones de una costurera" o los poemas dedicados a Lawrence de Arabia, incursionan también en esta búsqueda desde diferentes voces y estrategias. En "Meditaciones de una costurera 1", la degradación de la sujeto parte de la necesidad de una reconstrucción del cuerpo que está descosido y roto, lo que es signo de su marginalidad. Se equipara la necesidad del trabajo de hilar y coser a la de recuperar su propio cuerpo. La necesidad de coserse a sí misma se desarrolla a través del trabajo con la ropa y también de la escritura. El espacio en que se habita tiene fisuras, se vive en la basta del mundo, la tela es delgada y se termina tapándose con pasto, es decir con una apariencia que alguien le induce a ponerse: "El crepúsculo, una aguja oscura, apuñala la ciudad / y me da visiones de seguir carretes de hilo / milla tras milla por carreteras y campos / hasta habitar algún lugar en la basta del mundo". Todo el poema está marcado por el trabajo de hacer y rehacer una tela que quiere hacerse propia y personal, pero que está marcada por la marginalidad, la fragmentación, las fisuras y la ausencia, como un símbolo permanente de la situación de la mujer en el mundo: "y si no termino antes del atardecer / todo se despedazará de nuevo / las plataformas continentales se perderán lentamente en el mar / y los terremotos rajarán / los parches gastados de Asia... todo calza al final y alguien ha forrado con pasto / la delgada tela de esta vida que visto"15.

Los complejos poemas dedicados a Lawrence de Arabia (TheT.E. Lawrence

\footnotetext{
14 "Oscuros pinos bajo el agua" de MacEwen en Sagaris, op. cit., pp. 157-159.

15 "Meditaciones de una costurera 1" de MacEwen en Sagaris, op. cit., pp. 159-161.
}

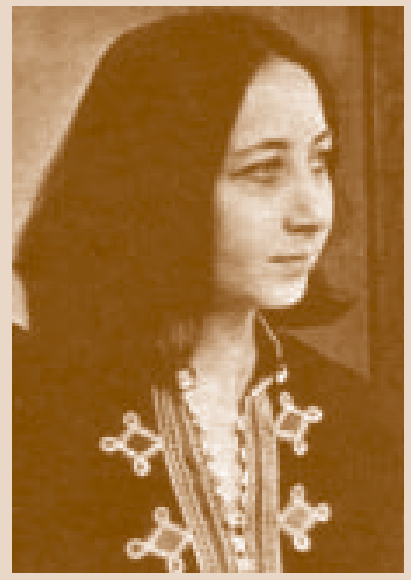

G. Mac Ewen 
Poems) tienen el doble carácter de integrarse a la visión de un homosexual reprimido y violado desde la perspectiva de una sujeto femenino y por lo tanto situarse en un vórtice que la focaliza desde lo masculino y lo femenino simultáneamente. Es como si la mirada bizca del espejo se volviera doble para mostrar la visión femenina de la violación, al mismo tiempo que se feminiza al hombre para sacarlo del género y expresar el conflicto desde una perspectiva más amplia y universal. Al revivir la violación desde un Otro que es él y ella, la poeta convierte el hecho en un símbolo que es capaz de ser visto desde lo transgenérico: "Lo que pasó obviamente fue que en Deraa fui violado / golpeado y azotado y reducido a trizas / por turcos con piojos en el pelo y enfermedades venéreas... Imagínate, yo nunca aguanté que me tocara nadie: Me consideraba una especie de flamante monje, terriblemente intacto, lleno de color / Inviolable es la palabra. / Pero todo es vergüenza, sabes, tener un cuerpo / es una broma cruel"16.

Sin la dramaticidad exacerbada y contenida a la vez de MacEwen, en la poeta chilena Marina Arrate ocurre algo similar, aunque en ella la búsqueda del origen no se arraiga en las raíces como en la poeta canadiense, sino en el pasado. Mientras la costurera de MacEwen hila su cuerpo en la marginalidad, la sujeto de Arrate se pone máscaras y tatuajes que la desarticulan del dominio patriarcal voyeurista. En el solipsismo de su propia reconstrucción como imagen de juego que la hace otra y la misma, que la desdobla y la autocontempla, la sujeto también se conoce y re-conoce. Aquí el espejo es el primer instrumento de este autorreconocimiento, pues a través de él se autoposee y se reivindica como pura apariencia, pero también como gesto de rebeldía contra un orden que condena el autoerotismo y que preconiza el reino de los fines. Expresa en M áscara negra (1990): "La mano entinta el pincel. / La mano izquierda cruza el rostro, estira el párpado derecho. / Con su pincel impregnado la pintora / audaz y más confiada tiñe / ahora horizontal progresiva apegada a la piel / una línea perfilada / sobre las pestañas del párpado superior. / $\mathrm{Al}$ igual que con el izquierdo / se desliza algunos milímetros más / alargando la comisura exterior del ojo / y simulando una extraña oblicuidad / penetra en el espejo el símil soñado / de una idea figurada. / La boca emite guturales sonidos placenteros, / una boca mojada y untuosa / desde ese ojo y medio semeja".

La 'máscara' del maquillaje y la marca superficial del 'tatuaje' ("por medio de cortes profundos / las cicatrices / por medio de heridas / amorosa y artificialmente abiertas / los queloides / por medio de trasplantes, / de piel de antílopes y jaguar / las nuestras") serán los elementos constituyentes de una rebelión que se instala en el goce del gesto de rehacerse a sí misma como pura superficie lúdica, pero también como reposesión del discurso y del

16 "Deraa” de MacEwen en Sagaris, op. cit., pp. 165-167. 
cuerpo en el acto de enmascararse. En el rito del maquillaje se va descubriendo la propia imagen que abre la posibilidad de la otra -la prófuga, la tránsfuga-, y reivindica la realización de una escritura distinta, también en perpetua fuga de sí misma. Usando el espejo como herramienta de autoconocimiento, la mirada oblicua, no contaminada, devuelve una imagen que se está creando recién en el acto de hacerse maquillaje o tatuaje, autocontemplación y goce, expectación y espectáculo, una sujeto que no se afirma en la racionalidad patriarcal, sino en su apariencia, en su sensualidad, en la ritualización de un goce estético que se hace conocimiento en su propio desgarro: "Se despeja el rostro de las manos / Dos ojos en el espejo / hechizados se contemplan. / Detrás de ese antifaz / de serpiente empalizada/ dos ojos absortos / embebidos de asombro/ palidecen". En Arrate, la búsqueda del espacio original que se quiere constituir de nuevo en fuente de placer se ritualiza en la imagen de la danzadora y su movimiento vertiginoso, que como la escritura culmina en el intento de situarse en un espacio y una producción propias, como se indica en el final de Máscara negra: "Plena, precisa y pausada / procederé a iniciar / la ceremonia / de mi propia coronación"17.

Entre erotismo y lenguaje, entre signo y cuerpo, Marina Arrate va descorriendo la tela de la escritura, estableciendo un hilo conductor entre memoria, cuerpo, lenguaje y existencia. La diferencia con otras escritoras coetáneas es que su escritura-placer rescata el goce de construir la carne frente a la carne, el placer de hacer(se) a sí misma. Sólo que este acto de signar(se) en la página con su cuerpo tiene un carácter transitorio, porque es un acto que se desplaza constantemente entre el destiempo de la memoria y el de su imaginario. Este desplazamiento tiene como pasadizo la metáfora del espejo que desdobla a la hablante entre la memoria olvidada y primigenia que busca reconstruirse y el espacio escritural-simbólico desde donde se explora el deseo. El espejo se constituye en el espacio multidireccional que se escinde en diversas posibilidades para la protagonista, entre ellas el deseo de ser la Otra pero desde ella misma, asistiendo a su propia representación y (auto) develamiento que la "inicia" en el goce de la existencia: "En el espejo la mujer... / ojo con ojo se miran en profundidad (...) penetra en el espejo / el símil soñado / de una idea figurada (...) Dos ojos en el espejo / hechizados se contemplan"18. Así, el gesto de la transformación se produce frente al espejo, en donde los fragmentos van dibujando la máscara que eligió para sí misma. En Marina Arrate, por lo tanto, el gesto de reconstrucción corporal y discursivo se traduce en recuperación de un contacto con la mujer ancestral, la maga de un ritual original que retiene los secretos de la sabiduría perdida.

\footnotetext{
${ }^{17}$ En M áscara negra de Marina Arrate (Santiago: Libros de Tierra Firme, 1996), pp. 11-22.

${ }^{18}$ Ibid, p. 14.
}

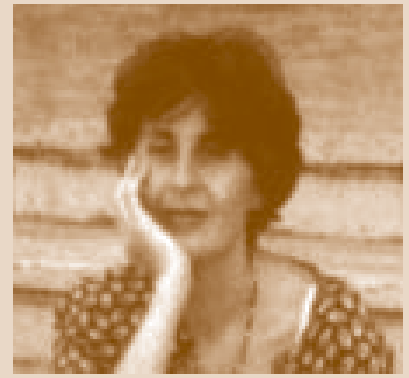

M. Arrate 


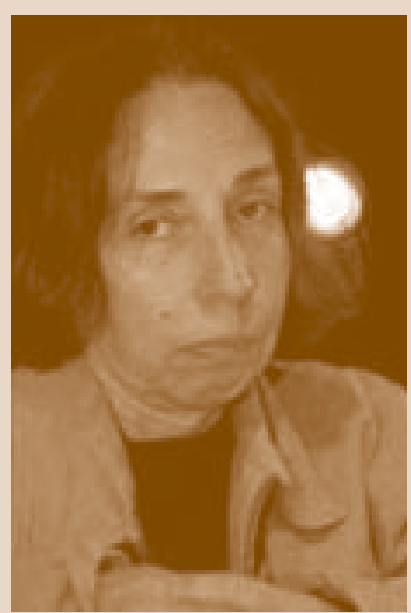

E. Hernández
Otra poeta chilena actual que busca la reconstrucción corporal desde la perspectiva del género es Elvira Hernández, pero en su caso la reconstrucción se hace incorporando la huella de la historia y por lo tanto es una crítica tanto al canon masculino individual como institucional. Su texto La bandera de Chile (1985) es un modo de habla poética que se construye en la alteración de la sintaxis oficial (en que se une lo patriarcal al pensamiento militar). A partir de la representación femenina de la bandera chilena se apropia del emblema-mujer-patria, desplazando el dominio que recae sobre esta imagen dictatorial-emblemática y cristalizando una presencia que se origina en el hablar(se). Se muestra en un cuerpo que comienza a (re)escribir(se), denunciando la ausencia de la mujer en el pensamiento oficial: "Nadie ha dicho una palabra sobre la Bandera de Chile / en el porte de la tela / en todo su desierto cuadrilongo / no la han nombrado / la Bandera de Chile ausente"19.

Hernández produce una analogía entre el cuerpo de la mujer y el cuerpo de la bandera: "La Bandera de Chile no dice nada sobre sí misma", porque le han arrebatado el lenguaje, "no importa ni madre que la parió". En este caso, su espejo está trizado y su imagen fragmentada, amenazada por la figura del padre que la inhabilita y la hace perder su pulsión anterior. Esto retrotrae el cuerpo de la mujer y de su lenguaje al vacío primigenio del desarraigo anterior a la protección maternal. Desde la orfandad del lenguaje, zona del vacío primigenio, donde parece que el cuerpo va a enmudecer y despojada de su origen materno, recupera trozos de su lengua aun exiliada y marginada: "La Bandera de Chile está tendida entre dos edificios / se infla su tela como una barriga ulcerada -cae como teta vieja- / como una carpa de circo/ con las piernas al aire tiene una rajita en el medio... / un hoyito para las cenizas del general O’Higgins / un ojo para la Avenida Bulnes". Aquí la escritura intenta recuperar la voz, materializando en el cuerpo lo que se piensa, identificándose con la madre y el cuerpo de la madre en la misma medida en que se anula la particularidad genérica y sexual de la sujeto y se la hace invisible: "Nadie la identifica en el charco donde vive / si la han visto no se acuerdan". No tiene lengua ni en el cuerpo ni en su discurso. Se desintegra su matriz genérica: "Banderillada pierde sangre". Remitida al espacio petrificado y marginal de lo privado, se dispone sobre ella una máscara-identidad anónima: "Los museos guardan la historia de la Bandera de Chile / disuelta anónima encubierta... y deshilachada es historia ya muerta".

Pero en el momento más radical de su encadenamiento, la palabra-mujer inicia el encuentro con su propia marginalidad a partir de su reconstrucción genérica. El discurso pasa de la denuncia a la resistencia, alterando el dominio a partir del desprendimiento de la lengua del invasor sobre la suya

\footnotetext{
${ }^{19}$ En La bandera de Chile de Elvira Hernández (Santiago: Libros de Tierra Firme, 1991), p. 9.
} 
propia: "De nuevo la saliva atorada de saliva la Bandera de Chile / de nuevo la boca escupe la chacarilla vomitosa sin especie aunque le cueste los dientes". Sacudida de la mordaza, al sujeto se arriesga hasta la cicatriz. Busca en su memoria anterior (inconsciente) para pulsar un gesto de (auto)recuperación que rescate la huella de resistencia: "la bandera tiene algo de señuelo que resiste / no valen las sentencias de los Jueces". Allí la jerarquía es invalidada y desalojada. Pero como la sujeto sabe que la resistencia puede ser espúrea, empieza a construir alternativas de movimiento convirtiendo su existencia en existencia tránsfuga ("la Bandera de Chile escapa a la calle"), instalándose en un espacio vacío y (auto)marginal ("el blanco exilio"... / donde / la Bandera de Chile declara dos puntos / su silencio" (20). Arraigada en un fibroso y móvil silencio de orfandad, la sujeto del texto inicia la relectura de su cuerpo y de su lengua por medio de un movimiento de resignificación genérica.

En su heterogénea construcción corporal y discursiva, las visiones se cruzan y dialogan: lengua entrecortada, móvil y multisémica la de Elvira Hernández, para construir la denuncia y la resistencia; enmascaramiento y cicatriz en Marina Arrate para evadir el dominio del Otro a través de la reconstrucción de lo Propio; liberación de la mujer encuevada que pugna por salir de su prisión de hielo y expresar su pasión reprimida por la sociedad en Jay MacPherson; enraizamiento en las profundidades del inconsciente para unir cuerpo y escritura en Gwendolyn MacEwen; disolución de las dualidades represivas encarnadas en los símbolos y mitos del sistema patriarcal en Margaret Atwood. En todas ellas, la geografía del espacio natural, las fragmentaciones y grietas de la escritura y las desmembraciones del cuerpo son parte de un vasto tejido que se hila, descose y recompone interminablemente para percibir y resistir los dominios del poder patriarcal, en cuyos vacíos e intersticios con diferentes estrategias textuales tejen un lenguaje común. Es en esa matriz original de simbolismos, temas y representaciones, terrenos a medio mostrar, donde encontramos los recursos que nos permiten comparar a estas escritoras, ratificando sus rasgos identitarios comunes, focalizados en elementos tales como el diálogo propio con la naturaleza, el redescubrimiento simbólico y concreto del cuerpo, la fuerza espasmódica de una oralidad-escritura, la rearticulación de las dicotomías, las diversas estrategias del delirio poético, las variables de la marginalidad, el desborde como centro móvil y tránsfuga, los recursos de la pluralidad, el simultaneísmo, los silencios y las rupturas frente al pensamiento racional.

En las poetas chilenas y canadienses, el mosaico que reproduce el espejo de experiencias genéricas comunes, represiones históricas similares y reconstrucciones vitales y escritura que afrontan las mismas pruebas y opciones de

${ }^{20}$ Ibid, p. 34. 
vida y las mismas estrategias retóricas, todos sus textos son el texto; esa tela que se urde en el vasto tejido de lo no dicho y de lo no pensado, pero que sigue esperando en la página en blanco.

\section{BIBLIOGRAFIA}

Arrate, Marina. 1996. M áscara negra. Santiago: Libros de Tierra Firme.

Atwood, Margaret. 1996. Survival. Toronto, Canada: McClelland \& Steward Inc.

Catalán, Carlos. 1985. Cinco estudios sobre cultura y sociedad. Santiago, Chile: FLACSO,

Denham, Paul. 1973. The Evolution of Canadian Literature in English. Ottawa, Canada: Holt, Rinehart and Winston of Canada Limited.

Hernández, Elvira. 1991. La bandera de Chile. Santiago, Chile: Libros de Tierra Firme.

Labarca, Amanda. 1947. Feminismo contemporáneo. Santiago, Chile: Zig-Zag.

Nómez, Naín. 1998. Poesía chilena contemporánea. Breve antología crítica. Santiago, Chile: Fondo de Cultura Económica,

Prentice, Alice et al. 1996. Canadian Women. A History. Toronto, Canada: Harcourt Brace and Co.

Sagaris, Lake, ed. 1986. Un pájaro es un poema. Santiago, Chile: Pehuén Editores.

Sullivan, Rosemary, ed. 1989. Poetry by Canadian Women. Toronto, Canada: Oxford University Press.

Valdés, Adriana. 1989. "Identidades tránsfugas", Una palabra cómplice. Encuentro con Gabriela M istral. Roma-Santiago: Isis Internacional, pp. 75-86.

Varias autoras. 1987. Escribir en los bordes. Santiago, Chile: Cuarto Propio.

Wilms Montt, Teresa. 1994. O bras completas. Ruth González-Vergara, ed. Santiago, Chile: Editorial Grijalbo. 